2

\title{
Writing difficulties in Alzheimer's disease and Mild Cognitive Impairment
}

(1)

Olivia Afonso ${ }^{1}$, Carlos J. Álvarez ${ }^{2}$, Carmen Martínez ${ }^{3}$, and Fernando Cuetos ${ }^{4}$

4

5

6

7

${ }^{1}$ Oxford Brookes University, Oxford, United Kingdom

${ }^{2}$ Universidad de La Laguna, Tenerife, Spain

${ }^{3}$ Hospital de Cabueñes, Gijón, Spain

${ }^{4}$ Universidad de Oviedo, Oviedo, Spain 
The present study addresses the scope of the writing difficulties observed in

3 patients with Alzheimer's disease (AD) and Mild Cognitive Impairment (MCI). Patients

4 with $\mathrm{AD}$, patients with $\mathrm{MCI}$ and healthy controls performed a written picture-naming

5 task and a direct copy transcoding task in which phonology-to-orthography (P-O)

6 consistency was manipulated. Written latencies, inter-letter durations, mean word pen

7 pressure and number of errors were measured. Results revealed that there was a

8 significant difference between the control group and both groups of patients in written

9 latencies and number of errors. However, in inter-letter interval or mean pen pressure

10 there were significant differences only between the group with $\mathrm{AD}$ and the other groups.

11 P-O consistency and the type of task produced similar effects in the three groups of

12 participants, suggesting a general deficit affecting the ability to access/generate

13 orthographic representations. The relevance of these results for understanding the

14 spelling impairment in AD and MCI are discussed.

17 Keywords: handwriting, Alzheimer's disease, Mild Cognitive Impairment, spelling-to-

18 dictation, copying 
Although language impairments in Alzheimer`s disease (AD) have been extensively documented, spelling and handwriting deficits have received considerably less attention. Difficulties in writing have often been reported in AD (Alzheimer, 1907 cited in Rodríguez-Ferreiro, Martínez, Pérez-Carbajal, \& Cuetos, 2014; Cuetos, Martínez, Martínez, Izura, \& Ellis, 2003; Onofri, Mercuri, Donato, Ricci, 2015; Rapcsak, Arthur, Bliklen, \& Rubens, 1989; Werner, Rosenblum, Bar-On, Heinik, \&

7 Korczyn, 2006) but only a few studies have focused on establishing the nature of the underlying deficit and its development throughout the evolution of the disease. Moreover, the scarce empirical evidence so far has been fairly inconclusive. Whether or not writing skills are impaired in early stages of $\mathrm{AD}$ and what is the pattern of deterioration in the components of the writing production system have been two of the most controversial topics in this area of research (Hughes, Graham, Patterson, \& Hodges, 1997; Luzzatti, Laiacona, \& Agazzi, 2003; Silveri, Corda, \& Di Nardo, 2007). In this study, we tested kinematic variables of the writing of patients and healthy

It has been claimed that writing abilities are affected only in the later stages of AD (Hughes et al., 1997; Cummings, Benson, Hill, \& Read, 1985). However, recent evidence has contradicted this assumption, with writing difficulties being observed at different stages (Cuetos et al., 2003; Werner et al., 2006). As a result, there is no agreement about whether writing deficits appear at an early stage of the disease, nor even about whether they are a constant feature in AD. The study of writing difficulties in mild cognitive impairment (MCI) may shed some light on this issue. MCI is a phase of cognitive decline that may progress to AD. Although not all of those diagnosed with MCI develop AD, research on this cognitive state between normal aging and dementia offers a unique opportunity to identify early indicators of AD. However, if research 
1 about writing deficits in AD patients is scarce, the evidence reported about these deficits

2 in mild cognitive impairment (MCI) is even more limited. The few studies that have

3 evaluated writing abilities in MCI have reported inconsistent results (Lambon Ralph,

4 Patterson, Graham, Dawson, \& Hodges, 2003; Werner et al., 2006). Werner and

5 colleagues observed that some kinematic measures of the handwriting process were

6 altered in MCI patients. Namely, these patients produced longer writing times and lower

7 mean pen pressure than healthy controls when they copied a paragraph, a grocery list, a

8 bank check or the alphabet. However, Lambon Ralph and colleagues did not observe

9 significant differences in spelling ability between patients with MCI and controls.

10 Conversely, patients diagnosed with mild AD differed significantly from controls in

11 both studies, suggesting that writing may be notably impaired at this stage of the

12 disease.

The difference in the findings reported in these previous studies may be due to several factors. First, both studies used different tasks. Werner et al. used several copying tasks, while Lambon Ralph et al. (2003) asked participants to spell to dictation. It is well known that different writing tasks entail different cognitive processes (Bonin, Meót, Lagarrigue, \& Roux, 2015). Thus, some tasks may be more sensitive to a given deficit than others. Second, different measures were chosen to assess writing ability in both studies. Werner and colleagues analysed the kinematic measures of the written response, while Lambon Ralph and colleagues (2003) took accuracy as a measure of spelling ability. It is possible that the analysis of writing times is a measure more sensitive to early signs of deterioration of writing production than the number of errors. An increase in writing times might be detected even before the written production system is sufficiently affected to produce more errors. Finally, chronometric variables reported by Werner et al. such as written latencies or writing durations may reveal 
subtle differences between patients and controls in the ability to access/generate orthographic representations (i.e., spelling or central processes) or produce letter forms (handwriting or peripheral processes). However, Lambon Ralph and colleagues seemed to focus on spelling errors. This is an important point, since it has been proposed that the pattern of deterioration in $\mathrm{AD}$ would evolve from the most central levels of spelling to the most peripheral aspects of handwriting.

\section{Central and peripheral processes on writing production}

In order to write a word, one needs to retrieve the appropriate orthographic representation (spelling) and the hand movements required to actually produce the retrieved sequence of letters (handwriting). Based on the influential model of writing proposed by Van Galen (1991), spelling is considered one of the so-called central processes of writing, while handwriting refers to the motor or peripheral processes. The distinction between central and peripheral processes is widely agreed and supported by behavioural and neuroimaging evidence (Graham, Patterson, \& Hodges, 1997; Purcell, Turkeltaub, Eden, \& Rapp, 2011). Traditionally, central processes had been investigated from a psycholinguistic point of view, while peripheral processes had been of interest mostly for motor theorists. However, during the last decades the availability of digitising tablets that provide precise information about the timing of the written response has led to an increase in the number of studies that analyse chronometric measures to study both type of processes simultaneously (Afonso, Suárez-Coalla, González-Martín, \& Cuetos, 2017; Kandel \& Perret, 2015; Roux, McKeeff, Grosjacques, Afonso, \& Kandel, 2013). In these studies the time required to initiate a response (written latency) is claimed to mainly reflect processing at the central levels, while the time dedicated to the actual production of the response (for example, writing 
1 durations or inter-letter intervals) are mainly considered measures of peripheral processing. However, evidence is accumulating about the fact that central processes continue to affect writing durations after the response has been initiated (Afonso,

Álvarez, \& Kandel, 2015; Delattre et al., 2006; Kandel \& Perret, 2015; Lambert,

Alamargot, Larocque, \& Caporossi, 2011; Roux et al., 2013). Thus, it seems that the

6

distinction between central and peripheral processes may be less clear-cut than originally thought, with both type of processes interacting during writing.

In Van Galen's model, peripheral processes include allographic selection, force, time and size controls and muscular adjustment. Impairment to this level of processing are referred to as peripheral dysgraphia and it is characterised by a disturbance in the correct production of the hand-movements and motor programs required to form legible letters (Graham et al., 1997). Although Van Galen conceived an undifferentiated spelling module in which orthographic codes are retrieved to represent utterances, most models of spelling propose different ways to access an orthographic representation.

According to the popular dual-route models (Houghton \& Zorzi, 2003;

Tainturier \& Rapp, 2001), spelling may be achieved by means of at least two different routes. The lexical route is thought to give access to the orthographic form of known words stored in the lexicon, while the sublexical route would provide a plausible spelling based on the correspondences between phonemes and graphemes existing in the language (Caramazza, 1988; Tainturier \& Rapp, 2001). The sublexical route could provide a correct spelling for words with regular phonology-to-orthography (P-O) correspondences, but lexical access would be required to correctly spell words with irregular P-O correspondences. The existence of both routes is supported by the wellestablished difference between two types of central dysgraphia: surface dysgraphia and phonological dysgraphia (Bub \& Kertesz, 1982; Caramazza, Miceli, Villa, \& Romani, 
1 1987). In surface dysgraphia, the lexical route of spelling is affected, so errors appear in

2 words with non-predictable spellings as a result of overreliance on the phoneme-to-

3 grapheme conversion procedures (Beauvois, \& \& Derouesné, 1981; Patterson, Marshall,

4 \& Coltheart, 1985). Phonological dysgraphia refers to an inability to correctly apply the

5 correspondences between phonemes and graphemes, resulting in a selective deficit

6 affecting unknown words and nonwords (Shallice, 1981).

$7 \quad$ An alternative to dual-route models may be found in the parallel-distributed

8 processing (PDP) models (Seidenberg \& McClelland, 1989). From this point of view,

9 the spelling system would be a distributed network of connections between three

10 different levels: semantic, orthographic and phonological. Activation would spread from

11 one level to another according to the weight of the connections. Thus, links between

12 phonology and orthography will be mediated by semantics (Graham, Patterson, \&

13 Hodges, 2000). This is a difference with dual-route models, which assume that the

14 sublexical route may be used to spell to dictation without any semantic involvement

15 (Cuetos, 1991).

In any case, both theoretical perspectives predict larger P-O consistency effects when semantic information is impaired (Cortese, Balota, Sergent-Marshall, \& Buckner, 2003). In dual-route models, this impairment would lead to overreliance on the sublexical route. In the context of PDP models only connections between phonology and orthography would be available, and these connections are thought to be weaker in P-O inconsistent correspondences than in consistent correspondences (Graham et al., 2000). This is an important issue for research in AD, since semantic deficits are a wellknown characteristic of the disease (Chertkow \& Bub, 1990; Hodges \& Patterson, 1995). In line with the predictions of dual-route and PDP models, increased effects of P- 
2 Carmol, Lepage, Aimard, \& Trillet, 1996; Graham et al., 2000; Hughes et al., 1997).

3 However, Cortese and colleagues (2003) proposed a third possibility to account for this

4 pattern. These authors suggested that particular difficulties with P-O inconsistent correspondences might appear as a consequence of reduced attentional control. They argued that attentional control mechanisms are necessary to select the correct spelling and inhibit the incorrect grapheme in those cases in which a phonological form can be orthographically represented in more than one way. Thus, impaired attentional control mechanisms would affect to a greater extent the spelling of words including P-O inconsistent than consistent correspondences.

\section{Central and peripheral processes of writing in AD and MCI}

Several studies have tried to determine how the writing difficulties exhibited by AD patients evolve according to the severity of the disease (Forbes, Shanks, \& Venneri, 2004; Hughes et al., 1997; Luzzati et al., 2003; Silveri et al., 2007). Findings from these studies seem to suggest that surface dysgraphia would be the most likely form of dysgraphia in patients with minimal $\mathrm{AD}$, and sublexical procedures would be increasingly affected as the disease progresses. Peripheral aspects of handwriting production will be affected only at later stages of the disease (Cuetos et al., 2003; Forbes et al., 2004; Hughes et al., 1997). In line with this idea, it has been reported that the majority of spelling errors produced by patients at the initial stages of $\mathrm{AD}$ are phonologically plausible (Forbes et al., 2004; Hughes et al., 1997; Rapcsak et al., 1989). However, the claim that phonologically implausible errors do not appear early in the course of the disease has not always been supported by the evidence. Some AD patients have shown a spelling performance consistent with phonological dysgraphia even at the 
1 early stages of the disease (Luzzatti et al., 2003), and the existence of a qualitative shift

2 in the error type made by patients has not been confirmed.

An important aspect of these previous studies is that they have focused on the analysis of the amount and type of errors made by patients. As discussed above, this may lead to an underestimation of the spelling deficits, which might only be detected once the deficits have reached a level of severity sufficient to produce errors. However, small differences between controls and patients may exist even before the writing difficulties had become apparent. For example, Afonso, Suárez-Coalla, and Cuetos (2015) observed increased written latencies and inter-letter interval (ILI) durations in a group of adults with developmental dyslexia as compared to controls in words that they could spell correctly. Only the study conducted by Werner and colleagues (2006) has reported online measures of the written response in $\mathrm{MCI}$ and $\mathrm{AD}$, but this study did not address the locus of the deficits underlying the difficulties observed.

In the present study, as well as number of errors, we measured written latencies (as a measure of central processing) and ILI durations (as a measure of peripheral processing) produced by $\mathrm{MCI}$ and $\mathrm{AD}$ patients in comparison to their healthy peers during writing. Although central processes may also affect writing durations (Kandel \& Perret, 2015; Lambert et al., 2011; Roux et al., 2013), effects appearing only in written latencies would be likely to reflect central processing. Similarly, effects observed only

\section{in ILI durations would be difficult to interpret as central effects cascading into}

production. Mean pen pressure exerted by participants was also analysed, as this variable has been found to differentiate between controls and MCI patients and between MCI patients and AD patients (Werner et al., 2006). However, it is unclear if this effect reflects central processing, peripheral processing or emotional factors. As in this previous study, we expect to find reduced pen pressure in the group with $\mathrm{AD}$ than in the 
control group, with the MCI showing an intermediate level of pen pressure. Moreover, we aimed to establish whether or not pen pressure is sensitive to linguistic variables (in this case, $\mathrm{P}-\mathrm{O}$ consistency) and if it can be taken as a measure of difficulty at the central levels of processing.

In order to detect potential differences between controls and patients in the use of the sublexical procedures of spelling, P-O consistency was manipulated in a set of words that were tested in two different writing tasks: a written picture-naming task and a direct copy transcoding task. The comparison of the same set of words in both tasks has several advantages. First, it allows us to establish whether patients with AD exhibit spelling difficulties only in semantic tasks (such as written picture naming) or whether they show spelling problems also when copying (i.e., when the orthographic representation is present). In the written picture-naming task (but not in the copying task) prior activation of semantics is necessary to access the orthographic representation (Bonin et al., 2015). Thus, if differences between the control group and the groups with $\mathrm{MCI}$ and $\mathrm{AD}$ emerge only in the written picture-naming task, this might indicate that writing difficulties in MCI and AD patients may be exclusively due to impaired semantic representations. Second, this design will allow us to obtain information about how the semantic information provided by the picture in the naming task modulates the effects of P-O consistency.

\section{Methods}

\section{Participants}

Thirty-two outpatients, sixteen of them with probable AD and sixteen with MCI, and sixteen healthy seniors, took part in this experiment. All of them were right-handed native Spanish speakers and they came from a similar socio-economic background. 
1 Participants with motor or perceptive disorders were not included in the sample.

2 Patients were selected by the neurology group of Cabueñes Hospital (Gijón, Spain) on

3 the basis of their medical history, information from a knowledgeable informant, a CT or

4 MRI scan, and a neuropsychological evaluation. The diagnosis of probable AD was

5 made according to the Neurological and Communicative Disorders and Stroke-

6 Alzheimer's Disease and Related Disorders (NINCDS-ARDA criteria; McKhann et al.,

7 1984; revised by McKhann et al., 2011). AD patients also met the DSM-IV criteria for

8 dementia of the Alzheimer's type (American Psychiatric Association, 2000). All of them

9 were mild AD patients. MCI patients met the criteria for mild cognitive impairment of

10 amnestic type (Petersen, Doody, Kurz, Mohs, Morris, Rabins, et al., 2001), experienced

11 no deficits in other cognitive abilities and their daily living functional activities

remained intact. Controls were healthy adult volunteers without known psychiatric

history, sensory deficiencies, or medical conditions that could impair performance on the neuropsychological tests. in their scores in the MiniMental State Evaluation test (MMSE, Folstein, Folstein, \& McHugh, 1975). A summary of the demographic characteristics of the participants is given in Table 1. Informed consent was obtained from all participants.

\section{Table 1}

Demographic data of controls, patients with Mild Cognitive Impairment (MCI), and patients with Alzheimer Disease (AD)

\begin{tabular}{lcccl}
\hline \multicolumn{1}{r}{ Variable } & Control & MCI & AD & \multicolumn{1}{c}{$T$-tests } \\
\hline Mean age & & & & Control vs MCI, $p=.38$; Control vs \\
(SD) & 73.94 & 75.5 & 72.62 & AD, $p=.80 ;$ MCI vs AD, $p=.37$ \\
& $(8.01)$ & $(6.74)$ & $(9.24)$ & \\
& & & & Control vs MCI, $p=.59$; Control vs
\end{tabular}


(SD)

Mean MMSE
$(1.41)$

$(1.63)$

29.62

27.25

$(0.62)$

\section{Note. $\mathrm{SD}=$ Standard deviation; MMSE =MiniMental Scale Evaluation test.}

2

3

4

\section{Materials}

The full set of stimuli is given in Appendix A. Experimental stimuli were selected from the LEXESP database (Sebastián-Gallés, Martí, Carreiras, \& Cuetos, 2000). Values for word frequency, word length, orthographic neighbourhood and number of syllables were provided by BuscaPalabras (Davis \& Perea, 2005). Age of acquisition values were obtained from the age of acquisition norms for elderly Spanish people (Cuetos, Samartino, \& Ellis, 2012). Sixteen words were selected as experimental stimuli and two additional words for the practice phase. Half of them were P-O inconsistent and the other half were P-O consistent. P-O inconsistent words included a $\mathrm{P}-\mathrm{O}$ inconsistent correspondence (TIJERAS, scissor) in a position representing a $\mathrm{P}-\mathrm{O}$ consistent correspondence in its match in the P-O consistent condition (TENEDOR, fork). Letters in other positions were matched by P-O consistency. P-O consistent and inconsistent stimuli were matched by word frequency, orthographic neighbourhood, age of acquisition and number of letters and syllables. Pictures used as experimental stimuli were selected from the coloured and shaded images set of Snodgrass and Vanderwartlike objects (Rossion \& Pourtois, 2004). Coloured images were used to facilitate object recognition and object naming (Price \& Humphreys, 1989). Pictures included in both P-

O consistency conditions were also matched by name agreement. $T$-tests were conducted to make sure that all the controlled variables did not significantly differ across conditions (all $t \mathrm{~s}<1$ ). 


\section{Apparatus}

Stimuli presentation and digital recording of the responses were controlled by Ductus (Guinet \& Kandel, 2010). The experiment was run on an Asus F9Eseries laptop. A WACOM Intuos 5 graphic tablet connected to the computer and an Intuos Inking Pen were used to register the participants' responses.

\section{Procedure}

The procedure of this experiment was approved by the Ethics Committee of the Cabueñes Hospital and the Ethics Committee of the Department of Psychology of the University of Oviedo. The experiment was conducted individually in a quiet room. For all the participants the written picture-naming task was conducted in first place.

In both the written picture-naming task and the direct copy transcoding task, a trial started with an auditory signal and a fixation point. The fixation point was replaced by the visual stimulus (a picture or a lowercase word) 1000 millisecond after the offset of the auditory signal. Participants had to write the word in upper case (print handwriting was not enforced) on a lined sheet of paper placed over the digitizer as quickly and as accurately as possible. In the direct copy transcoding task, their attention was called to the fact that they had to continue writing the words in upper case, in spite of the fact that they would see the stimulus in lower case. When they finished a response, participants were instructed to hold the pen over the next line of the response sheet but without making any contact with the paper. Then the experimenter clicked the left button of the mouse to start a new stimulus. The whole experiment lasted around 35 minutes. 

pressure and number of errors were submitted to different analyses of variance (ANOVAs) with P-O consistency (consistent vs. inconsistent) and task (written picture-

5 naming vs. direct copy transcoding) as within-subjects variables and group (control vs.

$6 \mathrm{MCI}$ vs. AD) as a between-subjects variable. Written latencies were measured as the

7 time between the stimulus onset and the first contact of the pen with the tablet. In the P-

$8 \mathrm{O}$ inconsistent condition ILI durations for the critical interval were measured as the time

9 between the last pen lift in the letter previous to the letter P-O inconsistent and the first

10 pen down in this particular letter. In the P-O consistent condition the interval in the same position was measured. Mean pen pressure for each word was calculated based on the pressure values given by the tablet Wacom 5 Intuos (1024 pressure levels). Data points where no pressure was detected by the tablet (pressure $=0$ ) were excluded from this calculation. Only correct responses were included in the analyses. Responses containing misspellings, self-corrections or those in which a response was not given or a recording error occurred were considered errors and removed from the analysis. For the analyses on critical ILI durations those responses in which the critical ILI was not produced were treated as error. If writing latencies or ILI durations were above or below 2 standard deviations from the mean by participant were also disregarded. Overall, $12 \%$ and $24 \%$ of the writing latencies and ILI durations were excluded from the analysis in the direct copy transcoding task and in the written picture-naming task respectively.

Analysis of errors. Mean accuracy and standard deviations for each group and condition are given in Table 2. The main effect of group was significant, $F(2,45)=5.65, p<.01, M S E=$ 
$11.89, \mathrm{n}_{\mathrm{p}}{ }^{2}=.2 . T$-tests revealed that the control group made significantly fewer errors

2 than the group with $\mathrm{MCI}, t(31)=1.98, p=.05$, and than the group with $\mathrm{AD}, t(31)=$

$33.73, p<.001$. Moreover, the group with $\mathrm{AD}$ made more errors than the group with

4 MCI, $t(31)=2, p<.05$. The main effect of task was also significant, $F(1,45)=26.11, p$

$5<.001, M S E=3.469, \mathrm{n}_{\mathrm{p}}^{2}=.37$. More errors were made in the written picture-naming

6 task than in direct copy transcoding. P-O consistency was also significant, $F(1,45)=$

$75.66, p<.05, M S E=.71, \eta_{\mathrm{p}}^{2}=.11$. P-O inconsistent words yielded more errors than P-O

8 consistent words. No other effects were significant, all $t \mathrm{~s}<1$.

In order to obtain more information about to what extent errors made in the written picture naming task were due to semantic deficits (namely, to inability to recognise the picture), the types of errors made by each group in this task were analysed. Errors were included in three categories: semantic (the name given was not acceptable for the picture or the participant expressed not to recognise the picture), phonologically plausible (errors had the same pronunciation than the target words), and letter errors (including substitutions, omissions, transpositions and intrusions nonphonologically plausible). Separate t-tests were conducted for each category. Results revealed that the control group produced marginally fewer semantic errors than the group with MCI, $t(31)=1.98, p=.06$, and significantly fewer semantic errors than the group with $\mathrm{AD}, \mathrm{t}(31)=3.48, p<.005$. However, there were no significant differences in the number of phonological plausible errors or letter errors made by the three groups, all $t \mathrm{~S}<1$

\section{Table 2}

Mean accuracy (\%) and standard deviations (in brackets) for each group and condition in the written picture-naming and in direct copy transcoding task 


\begin{tabular}{lcccc}
\hline \multicolumn{1}{c}{ Group } & P-O consistent & P-O inconsistent & P-O consistent & P-O inconsistent \\
\hline Control & $84(36)$ & $81(39)$ & $88(32)$ & $89(31)$ \\
MCI & $84(37)$ & $70(46)$ & $85(36)$ & $84(37)$ \\
AD & $66(47)$ & $66(48)$ & $85(36)$ & $77(42)$
\end{tabular}

1 Note. $\mathrm{P}-\mathrm{O}=$ phonology-to-orthography.

2

\section{Written latencies.}

Mean written latencies and standard deviations for each group and condition are given in Table 3. The effect of group was marginally significant, $F(2,45)=2.98, p$ $=.06, M S E=7,070,091.15, \mathrm{n}_{\mathrm{p}}^{2}=.12$. Planned comparisons revealed that there was not a significant difference between the written latencies produced by $\mathrm{AD}$ patients and $\mathrm{MCI}$ patients $(t=1.01)$. However, written latencies produced by the control group were significantly shorter than those produced by the group with MCI, $t(63)=2.73, p<.01$, and the group with $\mathrm{AD}, t(63)=4.59, p<.001$. A significant effect of task was observed, $F(1,45)=36.72, p<.001, M S E=32,700,000, \eta_{\mathrm{p}}{ }^{2}=.47$. Participants were faster in the copying task than in the written picture-naming task. The interaction between task and P-O consistency was also marginally significant, $F(1,45)=2.90, p=.09, M S E=$ $257,620.25, \eta_{p}^{2}=.06 . T$-tests showed that P-O consistency significantly affected written latencies in the direct copy transcoding task, $t(47)=3.33, p<.005$, but had no effect in the written picture-naming task $(\mathrm{t}<1)$. No other effects were significant, all $t \mathrm{~s}<1$.

\section{Table 3}

$$
\text { Mean written latencies and standard deviations (in brackets) for each group and }
$$
condition in the written picture-naming and in direct copy transcoding task 


\begin{tabular}{lllll}
\hline Control & $2835(713)$ & $2744(724)$ & $1957(509)$ & $2037(597)$ \\
MCI & $3164(1211)$ & $3171(1147)$ & $2475(881)$ & $2521(855)$ \\
AD & $3585(1029)$ & $3519(1303)$ & $2456(844)$ & $2620(837)$
\end{tabular}

1

2

3

4

Due to the slowing in written latencies associated to $\mathrm{AD}$ and MCI, the effects of the manipulated variables may have been magnified in these groups. To control for group-related slowing we conducted a new analysis on the z-score transform of the written latencies (Faust, Balota, Spieler, Ferraro, 1999). The ANOVA on these standardised latencies revealed a significant effect of task, $F(1,45)=45.13, p<.001$, $M S E=26.7, \eta_{p}^{2}=.5$. Latencies were shorter in the copying task. The interaction between task and P-O consistency remained marginally significant, $F(1,45)=3.08, p$ $=.09, M S E=.24, \eta_{\mathrm{p}}^{2}=.06$.

\section{Critical inter-letter interval durations.}

Two participants from the group with $\mathrm{AD}$ and two from the group with MCI were removed from the analysis of ILI durations because they wrote in lower-case letters and they did not systematically produce ILIs. Two participants from the control group matching them in age and years of education were also removed from the analysis. Mean ILI durations and standard deviations for each group and condition are shown in Table 4 . The effect of group was significant, $F(2,39)=9.78, p<.001, M S E=$ $1,305,526.08, \eta_{p}^{2}=.33$. Planned comparisons revealed that ILI durations were significantly longer in the group with $\mathrm{AD}$ than in the control group, $t(55)=6.66, p<$ .001, an in the group with $\mathrm{AD}$ than in the group with MCI, $t(55)=5.71, p<.001$.

However, the group with MCI and the control group did not differ in this variable, $t<1$. 
1 The main effect of P-O consistency was also significant, $F(1,39)=22.68, p<.001$,

$2 M S E=64,429.17, \eta_{\mathrm{p}}^{2}=.37$. Longer inter-letter intervals were produced before the P-O

3 inconsistent segments than before the P-O consistent segments. No other differences

4 were significant.

5

6

7

8

9

10

11

13

\section{Table 4}

Mean critical ILI duration and standard deviations (in brackets) for each group and condition in the written picture-naming and in direct copy transcoding task

\begin{tabular}{lcccc}
\hline \multirow{2}{*}{ Group } & \multicolumn{2}{c}{ Written picture-naming } & \multicolumn{2}{c}{ Direct copy transcoding } \\
\cline { 2 - 5 } & P-O consistent & P-O inconsistent & P-O consistent & P-O inconsistent \\
\hline Control & $242(73)$ & $301(136)$ & $236(86)$ & $267(108)$ \\
MCI & $257(113)$ & $289(109)$ & $299(154)$ & $328(128)$ \\
AD & $463(234)$ & $484(104)$ & $409(215)$ & $461(227)$
\end{tabular}

\section{Note. $\mathrm{P}-\mathrm{O}=$ phonology-to-orthography.}

\section{Mean word pen pressure.}

Mean written latencies and standard deviations for each group and condition are given in Table 5. The main effect of group was marginally significant, $F(2,39)=2.45, p$ $=.099, M S E=81,842.61, \eta_{\mathrm{p}}^{2}=.11$. Planned comparisons revealed that the group with $\mathrm{AD}$ exerted significantly less pressure with the pen than the group with $\mathrm{MCI}, t(55)=$ $2.9, p<.01$, and less than the control group, $t(55)=2.28, p<.05$. No other effects were significant, all $t \mathrm{~s}<1$. 
Mean pen pressure (and standard deviations) for each group and condition in the written picture-naming and in direct copy transcoding task

Written picture-naming Direct copy transcoding

\begin{tabular}{lcccc}
\hline \multicolumn{1}{c}{ Group } & P-O consistent & P-O inconsistent & P-O consistent & P-O inconsistent \\
\hline Control & $416(97)$ & $408(99)$ & $425(82)$ & $430(85)$ \\
MCI & $435(81)$ & $433(85)$ & $427(81)$ & $439(86)$ \\
AD & $392(140)$ & $392(154)$ & $375(142)$ & $371(132)$
\end{tabular}

$4 \quad$ Note. $\mathrm{P}-\mathrm{O}=$ phonology-to-orthography.

5

6

7

\section{Discussion}

In the present study, we aimed to establish whether or not patients suffering from $\mathrm{AD}$ and $\mathrm{MCI}$ showed impaired word writing abilities in comparison to their healthy peers. Participants performed two different writing tasks in which P-O consistency of the words to be written was manipulated: a written picture-naming and a direct copy transcoding task. Written latencies, inter-letter interval durations, mean word pen pressure and number of errors were analysed. Results revealed that the group with $\mathrm{AD}$ produced more errors, longer written latencies and ILI durations and lower mean pen pressure than the control group. The fact that the control group significantly outperformed the group with $\mathrm{AD}$ in all collected measures confirms that writing is affected in mild stages of the disease (Cuetos et al., 2003; Werner et al., 2006). The group with MCI produced similar written latencies to those produced by the group with AD. Patients with MCI also produced more errors than the control group, but significantly fewer than the group with $\mathrm{AD}$. It seems that the group with MCI already exhibits a slowing in the access to the orthographic representations, although they still have a larger number of spared representations than the group with AD. Interestingly, the group with MCI did not differ from the control group in ILI durations or pen 
1

2

3

4 the central levels of processing (Afonso \& Álvarez, 2011; Delattre, Bonin, \& Barry,

5 2006; Zhang \& Feng, 2017). Thus, the pattern of results reported here may be consistent

6 with an evolution of the writing difficulties from the most central level of processing

7 (which it would be already affected in MCI) that would progress to affect lower levels

8 of processing in mild AD. Consistent with this idea, the three groups did not differ in

9 the number of phonologically plausible or letter errors produced, but only in the number

pressure. Thus, we found no evidence of writing processes taking place after the initiation of the response being significantly affected in the group of patients with MCI.

It is widely agreed that increased written latencies reflect increased demands at of semantic errors made in the picture naming task. Both group of patients produced more semantic errors in this task (mostly related to inability to recognise the picture). This loss of semantic information may be at least partially responsible for the increased written latencies observed in MCI and AD. However, it is important to notice that reduced writing speed in patients was also observed in the copying task, suggesting that the underlying deficit is not restricted to object recognition.

Increased ILI durations observed in the AD group may reflect difficulties at the peripheral levels. As mentioned above, writing durations have been claimed to mainly tap into lower levels of processing. Although some authors have reported compelling evidence of the fact that central processes may cascade to affect writing durations (Afonso et al., 2015; Delattre et al., 2006; Kandel \& Perret, 2015; Lambert et al., 2011), it is unlikely that the pattern of results obtained here for ILI durations could be better explained by central rather than by lower processing levels. The fact that the group with MCI showed slowing in written latencies but not in ILI durations is difficult to conciliate with the idea of a common locus of impairment. However, the effect observed in ILI duration could alternatively reflect impaired ability to maintain/retrieve 
1 information from the orthographic working memory system (henceforth, OWM). In a

2 study conducted with dyslexic and non-dyslexic adults, Afonso and colleagues (2015)

3 observed that ILI durations were the kinematic variable that was the most sensitive to

4 word length. Word length effects have traditionally been related to additional processing

5 loads in the orthographic working memory system (Caramazza et al., 1987; Miceli,

6 Benvegnù, Capasso, \& Caramazza, 1997; Tainturier \& Rapp, 2003). The fact that AD

7 patients but not MCI patients showed longer ILI durations than the control group

8 suggests that processes related to letter selection are impaired in mild AD but still

9 spared in MCI. In sum, this effect may be related to difficulties in accessing the motor

10 programs for each letter or to OWM deficits. More research is necessary to establish the

11 underlying cause of this effect. However, it is unlikely that increased ILI durations are

12 due to impairment to central processes.

The fact that increased ILI durations and reduced pen pressure were observed in the group with $\mathrm{AD}$ but not in the group with MCI diverges form the pattern reported by Werner and colleagues (2006). In this previous study, the group with MCI adopted an intermediate position between controls and AD patients in almost all measures. It is difficult to compare both studies, given the considerable number of differences between them. However, some potential explanations for this discrepancy can be pointed out. First, the group with MCI in Werner et al.'s study obtained a slightly lower MMSE mean score (26.6 versus the 27.2 mean score obtained in the present study), which may translate into greater impairment. Another possibility is that differences in the languages tested in both studies had produced different outcomes. Werner et al. tested Hebrew participants and it might be that handwriting using the Hebrew script is more demanding in terms of motor processes that writing using the Spanish alphabet. It is also possible that the measure of ILI duration measure considered in our study is less 
1 sensitive than the measure of whole-word duration reported by these authors. Finally,

2 Werner et al. observed that kinematic variables poorly classified participants in their

3 MIC group, although the same variables together with cognitive functioning allowed the

4 correct classification of around a $70 \%$ of the participants in other groups. This might

5 indicate that writing abilities may be particularly variable in patients with MCI. It is

6 important to notice that none of these explanations necessarily challenges our main

7 conclusion. This is, the fact that writing difficulties associated to MCI and AD initially

8 affect higher levels of processing and evolve to affect lower levels of processing. Even

9 if we have failed to detect a real deficit affecting writing durations in MCI, this would

10 only indicate that at this stage of the disease this deficit is more subtle than the

11 impairment affecting higher levels of processing.

Patients with AD but not patients with MCI exerted less pressure with the pen in

the paper than controls. Decreased pen pressure in the AD group may confirm the presence of an impairment affecting more peripheral aspects of written production that would be absent in the MCI group. Additionally, the fact that neither P-O consistency nor the type of writing task being performed affected the mean pen pressure supports the idea that this variable taps into lower levels of processing. The paucity of studies systematically investigating mean pen pressure makes any interpretation of this effect tentative. Werner and colleagues also found decreased pen pressure in both MCI and $\mathrm{AD}$ patients as compared to healthy controls. In contrast, LaBargue and colleagues (1992) reported increased pen pressure in mild to moderate AD patients as compared to controls. What variables may affect pen pressure is an issue that requires further experimental evidence to be settled. Since we are unaware of studies reporting changes in this measure in the same participant depending on the characteristics of the task or 
1 the material, it is a possibility that observed differences between groups are merely due 2 to individual differences.

The effect of P-O consistency was similar for the three groups and in both tasks (the interaction between consistency and task only approached significance in written latencies). Patients and controls seemed to make use of the phonological information to a similar extent and in a relatively task-independent manner. The fact that phonological information had a similar impact in both tasks apparently contradicts the prediction made by dual-route models (Houghton \& Zorzi, 2003; Tainturier \& Rapp, 2001), as well as previous findings that evidenced a larger impact of lexico-semantic information in written picture naming than in spelling-to-dictation and copying (Bonin et al., 2015; Bonin, Roux, Barry, \& Canell, 2012). This may be explained by the largely transparent nature of the Spanish orthography, which may promote overreliance of Spanish speakers on phonological information to spell. This would also explain that both groups of patients showed a P-O consistency effect similar to the effect obtained for the control group. It is possible that the control group tested in the present study had also overrelied on phonological information to perform the writing tasks.

One might think that if the semantic system is impaired in MCI and/or AD patients a larger P-O consistency effect should be observed in participants in these groups than in unimpaired peers, as predicted by dual-route (Houghton \& Zorzi, 2003; Tainturier \& Rapp, 2001) and PDP (Seidenberg \& McClelland, 1989) models. Another possibility is that the increase in number of errors, writing times and pen pressure observed in the group with $\mathrm{AD}$ is better explained by general cognitive slowing rather than by specific difficulties with written language (Nebes, Brady, \& Huff, 1989). However, the different pattern observed for MCI on the different measures would be difficult to explain from this point of view. In any case, our results do not support the 
1 view that semantic deficits have a greater impact on $\mathrm{P}-\mathrm{O}$ inconsistent spellings in

2 Spanish, at least in the written picture naming and the delayed copying transcoding task. Altogether, our results are in line with previous findings indicating an evolution

4 of the writing deficits in AD from a deficit affecting central processes (which would be 5 already present in $\mathrm{MCI}$ ) to a later impairment affecting lower levels of processing.

6 However, deficits in the production of individual letters would be more likely to appear $7 \quad$ in mild states of Alzheimer's disease. 
2 Afonso, O. \& Álvarez, C. J. (2011). Phonological effects in handwriting production: evidence from the implicit priming paradigm. Journal of Experimental Psychology: Learning, Memory, and Cognition, 37, 1474-83. doi:10.1037/a0024515

Afonso, O., Álvarez, C. J., \& Kandel, S. (2015). Effects of grapheme-to-phoneme probability on writing durations. Memory \& Cognition, 43, 579-592. doi: $10.3758 / \mathrm{s} 13421-014-0489-8$

Afonso, O., Suárez-Coalla, P., \& Cuetos, F. (2015). Spelling impairments in Spanish dyslexic adults. Frontiers in Psychology, 6. doi: 0.3389/fpsyg.2015.00466

Afonso, O., Suárez-Coalla, P., González-Martín, N., \& Cuetos, F. (2017). The impact of word frequency on peripheral processes during handwriting: A matter of age. The Quarterly Journal of Experimental Psychology. Advance online publication. doi: $10.1080 / 17470218.2016 .1275713$

American Psychiatric Association. (2000). Diagnostic and statistical manual of mental disorders (4th ed., text rev.). doi:10.1176/appi.books.9780890423349.

Beauvois, M. F., \& Derouesné, J. (1981). Lexical or orthographic agraphia. Brain, 104, $21-49$.

Bonin, P., Méot, A., Lagarrigue, A., \& Roux, S. (2015).Written object naming, spellingto-dictation, and immediate copying: Different tasks, different pathways? Quarterly Journal of Experimental Psychology, 68, 1268-1294.

Bonin, P., Roux, S., Barry, C., \& Canell, L. (2012). Evidence for a limited-cascading account of written word naming. Journal of Experimental Psychology: Learning, Memory and Cognition, 38, 1741-1758.

Bub, D., \& Kertesz, A. (1982). Deep agraphia. Brain and Language, 17, 146-65.

Caramazza, A. (1988). Some aspects of language processing revealed through the 
analysis of acquired aphasia: The lexical system. Annual Review of Neuroscience, 11, 395-421.

Caramazza, A., Miceli, G., Villa, G., \& Romani, C. (1987). The role of the Graphemic Buffer in spelling: Evidence from a case of acquired dysgraphia. Cognition, 26, 59- 85.

Chertkow, H., \& Bub, D. (1990). Semantic memory loss in dementia of Alzheimer's type. Brain, 113, 397-417.

Cortese, M. J., Balota, D. A., Sergent-Marshall, S. D., \& Buckner, R. L. (2003). Spelling via semantics and phonology: Exploring the effects of age, Alzheimer's disease, and primary semantic impairment. Neuropsychologia, 41, 942-957.

Croisile, B., Brabant, M., Carmol, T., Lepage, Y., Aimard, G., \& Trillet, M. (1996). Comparison between oral and written spelling in Alzheimer disease. Brain and Language, 54, 361-387.

Cuetos, F. (1991). Psicología de la Escritura: Diagnóstico y Tratamiento de los Trastornos de Escritura. Madrid: Escuela Española, S.A.

Cuetos, F., Martínez, T., Martínez, C., Izura, C., \& Ellis, A. W. (2003). Lexical processing in Spanish patients with probable Alzheimer's disease. Cognitive Brain Research, 17, 549-561.

Cuetos, F., Samartino, T., \& Ellis, A. W. (2012). Age acquisition norms from elderly Spanish people: characteristics and the prediction of word recognition performance in Alzheimer's disease. Psicológica, 33, 59-76.

Cummings, J. L., Benson, F., Hill, M. A., \& Read, S. (1085). Aphasia in dementia of the Alzheimer type. Neurology, 35, 394-397. 
1 Davis, C. J., \& Perea, M. (2005). BuscaPalabras: A program for deriving orthographic and phonological neighborhood statistics and other psycholinguistic indices in Spanish. Behavior Research Methods, 37, 665-671.

Delattre, M., Bonin, P., \& Barry, C. (2006). Written Spelling to Dictation: Sound-tospelling regularity affects both writing latencies and durations. Journal of Experimental Psychology: Learning, Memory, and Cognition, 32, 1330-1340. doi: 10.1037/0278-7393.32.6.1330

Faust, M. E., Balota, D. A., Spieler, D. H., \& Ferraro, F. R. (1999). Individual differences in information processing rate and amount: Implications for group differences in response latency. Psychological Bulletin, 125, 777-799.

Folstein, M. F., Folstein, S. E., and McHugh, P. R. (1975). Mini-mental state: s practical method for grading the cognitive state of patients for the clinician. Journal of Psychiatric Research, 12, 189-198.

Forbes, K. E., Shanks, M. F. \& Venneri, A. (2004). The evolution of dysgraphia in Alzheimer's disease. Brain Research Bulletin, 63, 19-24.

Graham, N. L., Patterson, K., Hodges, J. R. (1997). Progressive dysgraphia: Cooccurrence of central and peripheral impairments. Cognitive neuropsychology, 14, 975-1005. http://dx.doi.org/10.1080/026432997381321

Graham, N. L., Patterson, K., Hodges, J. R. (2000). The impact of semantic memory impairment on spelling: Evidence from semantic dementia. Neuropsychologia, 8, 143-163.

Guinet, E., and Kandel, S. (2010). Ductus: A software package for the study of handwriting production. Behavior Research Methods, 42, 326-332.

Hodges, J. R., \& Patterson, K. (1995). Is semantic memory consistently impaired early in the course of Alzheimer's disease? Neuroanatomical and diagnostic 
implications. Neurospsychologia, 33, 441-459.

Houghton, G., \& Zorzi, M. (2003). Normal and impaired spelling in a connectionist dual-route architecture. Cognitive Neuropsychology, 20, 115-162.

Hughes, J. C., Graham, N., Patterson, K., \& Hodges, J. (1997). Dysgraphia in mild dementia of Alzheimer's type. Neuropsychologia, 35, 533-545.

Kandel, S., \& Perret, C. (2015). How does the interaction between spelling and motor processes build up during writing acquisition? Cognition, 136, 325-336. doi: 10.1016/j.cognition.2014.11.014

LaBarge, E., Smith, D. S., Dick, L., \& Storandt, M. (1992). Agraphia in dementia of the Alzheimer type. Archives of Neurology, 49, 1151-1156

Lambert, E., Alamargot, D., Larocque, D., \& Caporossi, G. (2011). Dynamics of the spelling process during a copy task: Effects of regularity and frequency. Canadian Journal of Experimental Psychology, 65(3), 141-150. doi: $10.1037 / \mathrm{a} 0022538$

Lambon Ralph, M. A., Patterson, K., Graham, N., Dawson, K., \& Hodges, J. R. (2003). Homogeneity and heterogeneity in mild cognitive impairment and Alzheimer's disease: a cross-sectional and longitudinal study of 55 cases. Brain: A journal of neurology, 126, 2350-2362. doi: 10.1093/brain/awg236

Luzzatti, C., Laiacona, M., \& Agazzi, D. (2003). Multiple patterns of writing disorders in dementia of the Alzheimer type and their evolution. Neuropsychologia, 41, $759-772$.

McKhann, G., Drachman, D., Folstein, M., Katzman, R., Price, D., \& Stadlan, E. M. (1984). Clinical diagnosis of Alzheimer's disease: report of the NINCDSADRDA work group under the auspices of the Department of Health and Human Services Task Force on Alzheimer's disease. Neurology, 34, 939-944. 
1 Miceli, G., Benvegnù, B., Capasso, R., \& Caramazza, A. (1997). The independence of phonological and orthographic forms: Evidence from aphasia. Cognitive Neuropsychology, 14, 35-69.

Nebes, R. D., Brady, C. B., \& Huff, F. J. (1989). Automatic and attentional mechanisms of semantic priming in Alzheimer's Disease. Journal of Clinical and Experimental Neuropsychology, 11, 219-230.

Onofri, E., Mercuri, M., Donato, G., Ricci, S. (2015). Cognitive fluctuations in connection to dysgraphia: A comparison of Alzheimer's disease with dementia Lewy bodies. Clinical Interventions in Aging, 10, 625-633.

Patterson, K. E., Marshall, J. C., Coltheart, M. (1985). Surface dyslexia. Hillsdale, NJ: Lawrence Erlbaum.

Petersen, R. C, Doody, R., Kurz, A., Mohs, R. C., Morris, J. C, Rabins, P. V., et al. (2001). Current concepts in mild cognitive impairment. Archives of Neurology, $58,1985-1992$.

Price, C., \& Humphreys, G. W. (1989). The effects of surface detail on object categorization and naming. The Quarterly Journal of Experimental Psychology, $41,797-827$.

Purcell, J. J., Turkeltaub, P. E., Eden, G. F., \& Rapp, B. (2011). Examining the central and peripheral processes of written word production through meta-analysis. Frontiers in Psychology, 2, 239. http://doi.org/10.3389/fpsyg.2011.00239

Rapcsak, S. Z., Arthur, S. A., Bliklen, D. A., \& Rubens, A. B. (1989). Lexical agraphia in Alzheimer's disease. Archives of Neurology, 46, 65-68.

Rodríguez-Ferreiro, J., Martínez, C., Pérez-Carbajal, A. J., \& Cuetos, F. (2014). Neural correlates of spelling difficulties in Alzheimer's disease. Neuropshycologia, 65, $12-17$. 
1 Rossion, B., \& Pourtois, G. (2004). Revisiting Snodgrass and Vanderwart's object set: The role of surface detail in basic-level object recognition. Perception, 33, 217 236.

Roux, J. S., McKeeff, T. J., Grosjacques, G., Afonso, O., \& Kandel, S. (2013). The interaction between central and peripheral processes in handwriting production Cognition, 127, 235-241.doi: 10.1016/j.cognition.2012.12.009

Sebastián-Gallés N., Martí M. A., Carreiras, M., Cuetos, F. (2000). LEXESP: Informatizado del Español. Barcelona: Ediciones de la Universitat de Barcelona.

Seidenberg, M. S., \& McClelland, J. L. (1989). A distributed developmental model of word recognition and naming. Psychological Review, 96, 523-68.

Shallice, T. (1981). Phonological agraphia and the lexical route in writing. Brain, 104, 413-29.

Silveri, M. C., Corda, F., \& Di Nardo, M. (2007). Central and peripheral aspects of writing disorders in Alzheimer's disease. Journal of Clinical and Experimental Neuropsychology, 29, 179-186.

Tainturier, M. J., \& Rapp, B. (2001). "The spelling process," in The Handbook of Cognitive Neuropsychology: What Deficits Reveal about the Human Mind, ed. B. Rapp. Philadelphia: Psychology Press, 263-289.

van Galen, G. P. (1991). Handwriting: Issues for a psychomotor theory. Human Movement Science, 10(2-3), 165-191. DOI: 10.1016/0167-9457(91)90003-G.

Werner, P., Rosenblum, S., Bar-On, G., Heinik, J., \& Korczyn, A. (2006). Handwriting process variables discriminating mild Alzheimer's disease and mild cognitive impairment. The Journals of Gerontology, 61, 228-236.

Zhang, Q., \& Feng, C. (2017). The interaction between central and peripheral processing in Chinese handwritten production: Evidence from the effect of 
Appendix A

2 Experimental stimuli used in the written picture-naming task and in the direct copy transcoding task.

\begin{tabular}{|c|c|c|c|c|c|c|c|}
\hline Words & WF & NL & NS & BF & $\mathbf{N}$ & AoA & NA \\
\hline \multicolumn{8}{|l|}{ Consistent } \\
\hline Ce_pillo & 5.18 & 7 & 3 & 201 & 1 & 3.93 & $89 \%$ \\
\hline Galli_na & 13.04 & 7 & 3 & 517 & 0 & 3.43 & $95 \%$ \\
\hline Le_ón & 30 & 4 & 2 & 172 & 2 & 5.13 & $100 \%$ \\
\hline Man_zana & 11.07 & 7 & 3 & 39 & 1 & 3.03 & $98 \%$ \\
\hline Mari_posa & 6.25 & 8 & 4 & 26 & 0 & 3.43 & $100 \%$ \\
\hline Rue da & 22.86 & 5 & 2 & 39 & 3 & 3.93 & $92 \%$ \\
\hline Te_nedor & 3.75 & 7 & 3 & 130 & 1 & 2.9 & $100 \%$ \\
\hline To_mate & 6.79 & 6 & 3 & 140 & 0 & 4.13 & $98 \%$ \\
\hline \multicolumn{8}{|l|}{ Inconsistent } \\
\hline Ár_bol & 35 & 5 & 2 & 35 & 0 & 3.2 & $97 \%$ \\
\hline Ca_ballo & 63.21 & 7 & 3 & 270 & 2 & 3.2 & $100 \%$ \\
\hline Cala baza & 2.5 & 8 & 4 & 24 & 0 & 4.27 & $87 \%$ \\
\hline Ce_bolla & 9.46 & 7 & 3 & 74 & 0 & 3.17 & $95 \%$ \\
\hline Cor_bata & 17.14 & 7 & 3 & 72 & 1 & 4.67 & $100 \%$ \\
\hline Esco_ba & 2.86 & 6 & 3 & 258 & 0 & 3.13 & $97 \%$ \\
\hline Glo_bo & 10.18 & 5 & 2 & 20 & 0 & 3.04 & $100 \%$ \\
\hline $\mathrm{Ti}$ jeras & 4.82 & 7 & 3 & 24 & 0 & 3.4 & $94 \%$ \\
\hline
\end{tabular}

3 Note. $\mathbf{W F}=$ word frequency; $\mathbf{N L}=$ number of letters; $\mathbf{N S}=$ number of syllables; $\mathbf{B F}=$ frequency of

4 the critical bigram; $\mathbf{N}=$ orthographic neighbourhood; $\mathbf{A o A}=$ age of acquisition; $\mathbf{N A}=$ name

5 agreement. The underscore symbol $\left(\_\right.$) marks the position of the critical inter-letter interval. 